\title{
RECURSOS Y USOS DEL AGUA EN EL ALTO Y MEDIO VINALOPÓ
}

\author{
Cipriano Juárez Sánchez-Rubio \\ Miguel Valdés Pastor
}

La principal misión de la Geografía Aplicada es contribuir a la ordenación del espacio. Ordenarlo implica tanto una decisión política como la aplicación de una serie de medios que ayudan a la población a alcanzar sus fines. Como el agua se ha convertido en el elemento fundamental del progreso económico y social es necesario planificarla con el objetivo de conseguir una óptima utilización de su potencial, puesto que las cantidades demandadas son cada vez mayores.

El aumento de la población, su cada vez mayor concentración en las grandes ciudades, el despegue del consumo por habitante y día, y el desarrollo industrial ponen de manifiesto que ha pasado el tiempo de facilidad para atender las demandas. En consecuencia, el mayor aprovechamiento del agua conlleva la exigencia de una gestión integrada dentro de la cuenca hidrográfica y en cada uno de los escalones de su utilización, indicándose que la explotación debe hacerse en condiciones tales que su uso no comprometa a otros posteriores cuando se restituya a su cauce. Por todo esto, se necesita conocer los recursos hídricos de cada una de estas unidades territoriales, el balance entre ellos y su demanda, y la contaminación admisible en sus puntos vitales ${ }^{1}$.

Evaluados los recursos superficiales y subterráneos y conocida la calidad que debe tener el agua, cabe preguntarse ¿a partir de qué bases se pueden preveer las necesidades futuras y cómo prepararnos para satisfacerlas? Las variables elegidas son el potencial demográfico apoyado en su crecimiento natural y una serie de normas previsibles de consumo en cada uno de los sectores demandantes. Por este motivo es necesario diferenciar las cantidades requeridas por la agricultura, industria y el abastecimiento, tanto en las zonas [174] urbanas como en las rurales, porque se debe tratar no sólo de incrementar los débitos disponibles sino lograr un mayor rendimiento.

Este último objetivo «comporta, en la agricultura, la mejora de los procedimientos del riego y la reducción de la evapotranspiración, sin olvidar que la economía del agua requiere, además de innovaciones técnicas, una serie de medidas legales tendentes a remover situaciones arbitrarias y antiproductivas ${ }^{2}$. Y en este sentido, hay que tratar de conseguir una disciplina del consumo, especialmente en la industria, porque cada vez son mayores las cantidades demandadas, ya que en la misma se incluyen no sólo la necesaria para el proceso productivo, sino también el flujo suficiente que permita diluir los contaminantes hasta el nivel de aceptable. Disciplina que debe hacerse extensiva al agua destinada a consumo doméstico puesto que vuelve a la circulación general con sobrecarga de residuos y necesitada de los mismos tratamientos.

\section{EL MARCO GEOECONÓMICO}

${ }^{1}$ PAÍS, 8-9-82, pág. 32. La mitad de la población mundial sólo llegará a beneficiarse de un agua de calidad en el año 1990, según ha puesto de manifiesto el Congreso Internacional sobre las Distribuciones de Agua, celebrado en Zurich (Suiza) en septiembre de 1982.

${ }^{2}$ MORALES GIL, A. y JUÁREZ SÁNCHEZ-RUBIO, C.: «Cambios en el uso del agua». Estudios Geográficos, 1981, N. ${ }^{\circ} 165$ pág. 376. 
La provincia de Alicante abarca una extensión de $5.819 \mathrm{Km}^{2}$ y se parcela, desde el punto de vista geográfico, en nueve grandes comarcas que no rebasan su límite administrativo. En algunas de ellas su historia influye decisivamente en su denominación mientras que en otras se ha recurrido a nombres fluviales dando prueba de una asepsia localista y permitiendo la subdivisión geográfica en Alto, Medio y Bajo. Éste es el caso de las dos comarcas objeto de estudio, ya que las mismas son conocidas, en el ámbito geográfico, como el Alto y Medio Vinalopó ${ }^{3}$. Sin embargo, el Ministerio de Agricultura parceló el territorio provincial, a efectos agrarios, en diez comarcas, número que ha reducido a la mitad, por lo que las dos comarcas geográficas han quedado integradas en una con el nombre de Vinalopó, localizada en el sector NO de la provincia. Ocupa una extensión de $1.491 \mathrm{Km}^{2}$, pero entre ambas comarcas existen diferencias no sólo en el aspecto físico sino también en los aprovechamientos derivados de la explotación agraria e industrial, lo cual se trasluce en la variedad de usos y cantidad de los caudales demandados.

El Alto Vinalopó pasa por ser una de las zonas más frías de la provincia donde las heladas se extienden desde finales de octubre hasta abril y las precipitaciones oscilan entre los 315 milímetros de Sax y los 459 de Biar, a 800 metros de altitud. El resultado es un clima semiárido con una necesidad de agua anual para los cultivos de 738 milímetros, con ningún o pequeño exceso de agua durante el año y un elevado grado de continentalidad producto del alto porcentaje acaparado por la concentración en verano de la eficacia térmica. Su tipología climática es $\mathrm{DB}_{2}{ }_{2} \mathrm{db}_{4}$ y la efectividad de las precipitaciones es mayor que en el sector medio puesto que sólo existen cuatro meses áridos y su déficit no rebasa los 360 milímetros. [175]

En el Medio Vinalopó las condiciones térmicas se atenúan. La media de enero en Monforte es de $11^{\circ}$ frente a los 5,9 de Villena, pero las precipitaciones disminuyen y la media municipal rara vez consigue los 300 milímetros: Novelda, 309,1, Pinoso 305,2, Aspe, 284, Monforte 278, etc. La tipología climática resultante es semejante al sector alto: $\mathrm{DB}_{3}{ }_{3} \mathrm{db}_{4}{ }_{4}$, mientras el número de meses áridos se eleva a nueve y el déficit de agua supera los 560 milímetros.

La precipitación media anual del Vinalopó (se incluyen también los datos de Bocairente y Jumilla-Yecla, por lo que la superficie se amplía hasta $1.660 \mathrm{Km}^{2}$ ) se eleva a 394,8 milímetros y el consumo por evapotranspiración a 353,8 milímetros. El balance hídrico arroja una escorrentía total de 41 milímetros que se reparten de manera muy desigual entre la escorrentía superficial, de 6,15 a 8,20 milímetros, y la subterránea, de 32,80 a 34,85 milímetros ${ }^{4}$. En consecuencia, cada año se reciben $655,36 \mathrm{hm}^{3}$ de agua y se gastan por evapotranspiración 587,30 $\mathrm{hm}^{3}$. Este agua que escapa a la evapotranspiración, $68,06 \mathrm{hm}^{3}$ anuales, el 10,39\% de la recibida, es la única de que se dispone para el consumo, y de ahí el nombre de lluvia útil propuesto en España a partir de $1971^{5}$.

${ }^{3}$ ROSSELLÓ VERGER, V. M. ${ }^{\text {a: }}$ «Ensayo de una división comarcal de la provincia de Alicante». Saitabi, XIV, págs. 155-177.

${ }^{4}$ MINISTERIO DE INDUSTRIA Y MINISTERIO DE AGRICULTURA. Estudio Hidrogeológico del Medio y Alto Vinalopó (Mecanografiado). Alicante 1979 pág. 12. «El análisis de hidrogramas parece indicar que la escorrentía superficial media se sitúa entre el 15 y el $20 \%$ de la escorrentía total».

${ }^{5}$ MINISTERIO DE INDUSTRIA. DIRECCIÓN GENERAL DE MINAS: Programa Nacional de Investigación Minera: Instituto Geológico y Minero de España. Madrid 1971, pág. 28. Las disponibilidades potenciales de agua, concepto equivalente a lluvia útil o escorrentía total, representa el agua de lluvia que escapa a la evapotranspiración y que corre sobre el terreno o se infiltra en él. Las siguientes fórmulas aclaran los anteriores conceptos:

$\mathrm{P}=\mathrm{ETR}+\mathrm{Lu}$

$\mathrm{Lu}=\mathrm{E}+\mathrm{I}$

siendo $\mathrm{P}=$ Pluviosidad 
En este marco geográfico es donde desarrolla su vida una población que según el censo de 1970 era de 161.119 habitantes de hecho y que en marzo de 1981 es de 188.447 habitantes. Se ha producido un incremento de 27.328 personas que se reparten muy desigualmente a lo largo del intercensal 70-81, puesto que en el primer quinquenio el aumento ha sido mucho más espectacular, $65,77 \%$, que en el segundo, $34,23 \%$. Esto determina que el incremento medio anual no acumulado sea durante la década de $1,16 \%$ y que dicho valor se obtenga por los altos porcentajes del período 1970-75, ya que en el segundo período dicho índice sólo es del 0,5\% anual. El resultado es que la densidad demográfica, referida solamente a los municipios alicantinos, pase de 108 habitantes en 1970 a 126 en 1981 cuando la media provincial ascendió en cada uno de dichos años a 158 y 197 habitantes, respectivamente. [176]

La población activa supone un $35 \%$ del total, pero la contribución es muy diferente entre ambas comarcas. En el Alto Vinalopó ${ }^{6}$ la distribución en 1975 era: agricultura 14,1\%, industria $62,1 \%$ y servicios $23,8 \%$ y ésta permanece estabilizada en 1980 , fecha en la que el Medio Vinalopó la repartía en: agricultura $24,9 \%$, industria $54,64 \%$ y servicios $20,46 \%{ }^{7}$. Tal fraccionamiento nos indica claramente que las comarcas tienen fuerte tendencia a la industrialización, existiendo un gran desequilibrio social, acentuado en localidades como Bañeres, Elda, Monóvar y Petrel, donde la población activa agraria es inferior al 8\%, mientras en Monforte es del 53,5\%.

Durante este período, el espacio agrario ocupado por el regadío (que implica una mayor demanda de agua) pasa de 17.386 ha a 27.104 ha, siendo la distribución geográfica de su tasa de crecimiento muy desigual, de tal forma que en el Alto Vinalopó el incremento fue de 2,35\% entre 1975 y 1980, mientras que en el Vinalopó Medio es del 14,23\% ${ }^{8}$. Esto se explica porque paliado el factor limitativo, el agua, la transformación de tierras de secano a regadío requiere grandes inversiones de capital. Tales desembolsos provocan un encarecimiento de los costes de producción que solamente resisten aquellos cultivos cuya rentabilidad es lo suficientemente alta para absorberlos. Éste es el caso de la uva de mesa, base de la expansión del regadío en el área meridional y cuya explotación se hace prohibitiva en el Alto Vinalopó a causa de su dureza climática. De ahí que el rendimiento bruto por hectárea de superficie labrada fuera en 1975 de 28.400 pesetas en el Alto Vinalopó y de 41.500 pesetas en el Medio, mientras que en regadío la diferencia es más acusada, al obtenerse 63.900 pesetas, en el Alto y 108.900 pesetas en el Medio, el mayor de la provincia.

Como consecuencia, la producción final agraria, que en 1976 suponía el 22\% de la provincia con el predominio del sector agrícola (agrícola 91,8\%, ganadero 7,40\%, y forestal $0,8 \%$ ), se modifica en 1981 al aumentar el $24,6 \%$ y los subsectores desequilibrarse aún más puesto que el agrícola se eleva al 93\%, reduciéndose el ganadero al 6,20 y el forestal al 0,60. De

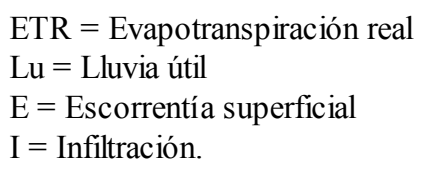

${ }^{6}$ MATARREDONA, COLL, E: El Alto Vinalopó. Universidad de Alicante (en prensa).

${ }^{7}$ CAJA DE AHORROS DE ALICANTE Y MURCIA: Alicante 1981. Págs. 46 y 47. No se han tenido en cuenta la Algueña, Hondón de las Nieves y Hondón de los Frailes por carecer de datos. En cualquier caso, tales índices se ven modificados si se acepta la propuesta media de los municipios de menos de 2.000 habitantes cuya distribución es: agricultura $59,3 \%$, industria $32,3 \%$ y servicios $8,5 \%$.

8 JUÁREZ SÁNCHEZ-RUBIO, C.: «El uso del espacio agrario en la provincia de Alicante». Investigaciones Geográficas, 1982, número 1 pág. 81. Los índices del Alto y Medio Vinalopó eran, en 1975, de 17’40 y 28’06, respectivamente. En 1980 tales valores se elevan a 19'75 y 42’49, en el mismo orden. 
esta forma, la renta comarcal que en 1970 ascendía a 9.525 millones de pesetas y suponía el 18\% de la provincia, se despega hasta lograr en 1981 los 73.300 millones de pesetas, equivalente al $21 \%$ de la renta provincial, cuando la extensión superficial es de $25 \%$ y el porcentaje de población del 16\%. [177]

\section{RECURSOS Y USOS DEL AGUA}

\section{Recursos}

El balance hídrico de una cuenca hidrográfica o de sus escalones y la determinación de los valores de la escorrentía superficial y subterránea confirman las disponibilidades de agua o recursos potenciales que pueden ser satisfechas por la demanda en cualquier lugar y tiempo. Como en la Cuenca del Vinalopó no existe concordancia entre las precipitaciones y la demanda, ha sido necesario la regulación de los caudales mediante presas y captaciones subterráneas. A las construcciones de embalses se ha unido la búsqueda de agua en el subsuelo. Se desea aprovechar en lo posible las precipitaciones que llegan al suelo y no terminan en el mar ni quedan retenidas por la vegetación o revierten mediante la evaporación a la atmósfera. Por este motivo, los estudios higrogeológicos se han multiplicado y estos almacenes interiores han sido el soporte de las mayores transformaciones agrarias y desarrollo industrial y urbano de la cuenca del Vinalopó, Júcar, Sur, etc. Pero la sobreexplotación de los mantos hipogeos ha producido un descenso alarmante en los niveles piezométricos. Ante esta situación ha surgido el proyecto de modificar, mediante trasvases, las grandes diferencias que ofrecen en caudal las vertientes generales.

Todo es consecuencia de que el agua se ha hecho un bien escaso, no sólo en estas comarcas sino también en la provincia, y que la carencia de tales recursos puede condicionar una gran parte de la actividad humana, por lo que resulta imprescindible una planificación hidrológica integral donde se cuente tanto con los caudales superficiales como con los subterráneos, olvidándose del régimen de propiedad y aprovechándose de la tecnología para reutilizar las aguas residuales. Y es que el aumento de la demanda obliga a la reutilización de las aguas procedentes de los centros urbanos de fuerte vertido, cuyo tratamiento se lleva a efecto por la depuradora de Elda. En la actualidad ésta regenera $10.500 \mathrm{~m}^{3}$ diarios sin ningún uso posterior. Como el porcentaje de reutilización ha sido cifrado en un $75 \%$ del volumen utilizado, este caudal será en el futuro el que permita atender gran parte de la superficie transformada y el aumento de la misma?.

Según los cálculos realizados, la escorrentía superficial de la cuenca Alta y Media oscila entre 10,20 y $13,60 \mathrm{hm}^{3} /$ año, mientras la subterránea se cifra entre 54,44 y $57,80 \mathrm{hm}^{3} /$ año. Pero la cuenca estructural o interior no coincide con la superficial, la cual vierte aguas al colector general desde la línea de cumbres que establecen las divisorias con las cuencas topográficas limítrofes. [178] En consecuencia, la cuenca estructural del Vinalopó se subdivide en una serie de sistemas de acuíferos diferentes en extensión, reservas, profundidad del agua, explotación, calidad, descenso medio anual de las reservas, etc., sobre cuyo aprovechamiento se asienta el potencial económico de la zona.

\section{Utilización actual del agua}

\footnotetext{
${ }^{9}$ INFORMACIÓN. 9-5-82. El contrato privado de compra-venta de aguas residuales depuradas que han suscrito con EMARASA las SS.AA.TT. números 13.252, 18.781 y 2.336, estipula un caudal de 350 litros/segundo con un mínimo anual de tres millones de metros cúbicos. Este plan posibilitaría el riego de un total de 8.300 ha, distribuidas así: Agost 1.700, Alicante Norte 3.200 y Monforte del Cid 3.400.
} 
El regadío utiliza la mayor cantidad de agua consumida en la comarca agraria del Vinalopó. La superficie regada en 1981 es de 27.014 ha, que se reparte muy desigualmente entre ambas subcomarcas, ya que el sector medio acapara el 69,70\%, más del doble, frente al 30,3\% del sector alto (cuadro 1).

CUADRO NUMERO 1

DEMANDA AGRICOLA EN 1981

\begin{tabular}{|c|c|c|c|}
\hline \multirow[t]{2}{*}{ TERMINO MUNICIPAL } & \multirow{2}{*}{$\begin{array}{l}\text { Superficie } \\
\text { regadio (Ha.) }\end{array}$} & \multicolumn{2}{|c|}{ Demanda teórica total } \\
\hline & & $\mathrm{m}^{3} / \mathrm{Ha}$./año & $\mathrm{Hm}^{3}{ }^{3}$ \\
\hline AGOST & 2.101 & 3.520 & 7,3955 \\
\hline ASPE & 3.713 & 3.855 & 14,3136 \\
\hline ELDA & 735 & 2.582 & 1,8978 \\
\hline HONDON NIEVES & 1.200 & 2.543 & 3,0516 \\
\hline HONDON FRAILES & 128 & 2.450 & 0,3136 \\
\hline MONFORTE DEL CID & 4.316 & 3.647 & 15,7405 \\
\hline MONOVAR & 2.103 & 2.007 & 4,2207 \\
\hline NOVELDA & 3,190 & 3.159 & 10,0772 \\
\hline PETREL & 125 & 2.249 & 0,2811 \\
\hline LA ROMANA & 1.219 & 2.578 & 3,1426 \\
\hline VINALOPO MEDIO & 18.830 & 3.209 & 60,4342 \\
\hline BAÑERES & 259 & 4.863 & 1,2595 \\
\hline BENEJAMA & 598 & 4.553 & 2,7227 \\
\hline BIAR & 535 & 3.540 & 1,8939 \\
\hline CAMPO DE MIRRA & 185 & 4.086 & 0,7559 \\
\hline CAÑADA & 201 & 2.558 & 0,5142 \\
\hline SALINAS & 337 & 4.229 & 1,4252 \\
\hline SAX & 619 & 2.128 & 1,3172 \\
\hline VILLENA & 5.540 & 3.546 & 19,6466 \\
\hline VINALOPO ALTO & 8.274 & 3.570 & 29,5352 \\
\hline TOTAL COMARCAL & 27.104 & 3.320 & 29,5352 \\
\hline
\end{tabular}

\section{[179]}

Para atender sus requerimientos se necesita un volumen teórico anual de $89,96 \mathrm{hm}^{3}$ que se distribuye en: $60,43 \mathrm{hm}^{3} /$ año, el 67,2\% para atender al Medio Vinalopó y 29,53 $\mathrm{hm}^{3} /$ año, el $32,8 \%$ a la zona alta. Sin embargo, esta necesidad hídrica teórica nunca se satisface totalmente sino que lo hace solamente en un $75 \%$ aproximadamente, lo que representa un consumo anual de $67,70 \mathrm{hm}^{3} /$ año y una infradotación de $22,26 \mathrm{hm}^{3}$.

Aunque esta infradotación pudiera pensarse que es debida a la escasez de la oferta de agua (que es una realidad), su explicación se debe a tres circunstancias: 1) Que existe una relación de intercambio negativa en cultivos como el almendro, vid, olivo, manzano y algunos herbáceos, puesto que de 1976 a 1981, la relación entre precios percibidos por los productos y precios pagados por el agricultor (inputs más salarios) presenta un deterioro continuado, que hace poco rentable la utilización a niveles deseables del input-agua; 2) a que se reciben lluvias en época de riego, lo cual permite no consumir caudales regulados y 3) a la introducción de técnicas que disminuyen el consumo de agua, tales como los riegos localizados (goteo, etc.). Por 
tales motivos el consumo real es sólo de un 75\% aproximadamente de la demanda teórica.

Un análisis comparativo entre la demanda teórica total, la cantidad específica de cada cultivo, y el número de hectáreas transformadas, revela los contrastes internos de sus necesidades y su tendencia futura. Así, el $69,70 \%$ de la superficie regada está localizada en el Medio Vinalopó y consume el 67,2\% del agua, mientras el resto comarcal sólo abarca el 30,3\% del territorio y consume el 32,8\% del agua. Si la comparación se realiza a nivel de cultivos, la uva de mesa acapara el $41,39 \%$ del agua requerida frente al $42,95 \%$ de la superficie regada. Pero esta situación cambia cuando el análisis se hace extensivo a otra serie de cultivos, ya que los porcentajes de la demanda son siempre superiores a los obtenidos por la superficie transformada (Cuadro 2), siendo verdaderamente significativo en los cereales, manzano y ciruelo.

Cuando el análisis se realiza en base a la distribución espacial y del número de hectáreas ocupadas por cada cultivo (Cuadro 3) se comprueba que en Alto Vinalopó predomina el cereal, manzano y almendro, frente a la zona media donde el aprovechamiento dominante es la uva de mesa y, en menor cuantía, la vinificación y el almendro. Se comprende, por tanto, que debido a las necesidades hídricas de los cultivos principales, la oportunidad de la precipitación en los períodos críticos (cereales), su resistencia a la aridez (almendro) y el alza continuada del precio del agua, hace que no se llegue a consumir el volumen teórico calculado.

La superficie regada se abastece casi totalmente con aguas subterráneas y el resto con aguas residuales que mezcladas con aquéllas mejoran su calidad. Actualmente se están efectuando las obras de elevación necesarias para transportar las aguas residuales del municipio de Alicante con destino a los regadíos del Medio Vinalopó. Así, en cuestión de pocos meses, 350 1/seg. posibilitarán el riego total de 8.300 ha de las que 1.700 son de Agost, 3.200 de Alicante Norte y 3.400 de Monforte del Cid. [180]

CUADRO NUMERO 2

DEMANDA AGRICOLA DE AGUA EN 1981 SEGUN CULTIVOS

\begin{tabular}{|c|c|c|c|c|c|c|c|c|c|c|c|}
\hline cultivos & $\begin{array}{l}\text { Herbá- } \\
\text { ceos }\end{array}$ & $\begin{array}{l}\text { Uva } \\
\text { mesa }\end{array}$ & $\begin{array}{l}\text { Uva } \\
\text { Vinf. }\end{array}$ & $\begin{array}{l}\text { Manzal } \\
\text { no }\end{array}$ & Peral & $\begin{array}{l}\text { Melo- } \\
\text { cosón }\end{array}$ & $\begin{array}{c}\text { Cirue } \\
\text { to }\end{array}$ & $\begin{array}{c}\text { Almen. } \\
\text { dro }\end{array}$ & Olivar & $\begin{array}{l}\text { Otros } \\
\text { Frut. }\end{array}$ & $\begin{array}{l}\text { Total } \\
\text { com. }\end{array}$ \\
\hline $\begin{array}{l}\text { Superficie } \\
\text { comarcal }\end{array}$ & 4,185 & 11.638 & 3.795 & 53.208 & 695 & 427 & 158 & 2.432 & 491 & 75 & 27.104 \\
\hline $\begin{array}{l}\text { Distrib. } \\
\text { Porcentual } \%\end{array}$ & 15.44 & 42.95 & 14,00 & 11,84 & 2,56 & 1,57 & 0.58 & 8,98 & 1.81 & 0.27 & 100 \\
\hline $\begin{array}{l}\text { Necesidades de agua } \\
\left(\mathrm{M}^{3} / \mathrm{Ha} / \mathrm{añ} \mathrm{O}\right)\end{array}$ & 4.330 & 3.200 & 1.500 & 5.040 & 4.600 & 4.600 & 4,600 & 2.360 & 1.500 & 4.600 & 3.335 \\
\hline $\begin{array}{l}\text { Demanda teórica } \\
\left(\mathrm{Hm}^{3}\right)\end{array}$ & 18.156 & 37.242 & 5.693 & 16.168 & 3.197 & 1.964 & 9.727 & 5.740 & 0.737 & 0,345 & 89,960 \\
\hline
\end{tabular}

\section{b) Utilización para industria y abastecimiento urbano}

Las necesidades se determinan, generalmente, en relación con el clima, las costumbres de limpieza, número de habitantes, su nivel de desarrollo industrial y las circunstancias locales.

En 1969 se indicaba que la cantidad de agua precisa en la mayor parte de los países para la alimentación humana y la satisfacción de las necesidades biológicas no debían ser inferiores a $150 \mathrm{l} / \mathrm{h} / \mathrm{d}$. A pesar de ello, en numerosas localidades, sobre todo rurales, el consumo no alcanzaba los 100 litros, mientras en otras, mucho más desarrolladas, tales niveles oscilaban entre 400 ó 500 1/h/d. La realidad era que, en 1969, la media española de las capitales de provincia alcanzaba $243 \mathrm{l} / \mathrm{h} / \mathrm{d}$, mientras en los municipios de más de 10.000 habitantes la cifra quedaba reducida a $126 \mathrm{l} / \mathrm{h} / \mathrm{d}$. 
No obstante, el modelo elegido para el cálculo de la demanda en las comarcas sigue las normas propuestas por el Plan Nacional de Abastecimientos y Saneamientos en el que se establecen unos determinados niveles, corregidos en función de las tasas de crecimiento demográfico y aumento del nivel de vida ${ }^{10}$. [181]

CUADRO NUMERO 3

DISTRIBUCION DE LA SUPERFICIE REGADA EN 1981

\begin{tabular}{|c|c|c|c|c|c|c|c|c|c|c|c|}
\hline $\begin{array}{l}\text { TERMINO } \\
\text { MUNICIPAL }\end{array}$ & $\begin{array}{l}\text { Herbá- } \\
\text { ceos }\end{array}$ & $\begin{array}{l}\text { Uva } \\
\text { Mesa }\end{array}$ & $\begin{array}{c}\text { Uva } \\
\text { Vinif. }\end{array}$ & $\begin{array}{c}\text { Manza- } \\
\text { no }\end{array}$ & Peral & $\begin{array}{l}\text { Melo- } \\
\text { cotón }\end{array}$ & $\begin{array}{c}\text { Cirue } \\
\text { lo }\end{array}$ & $\begin{array}{l}\text { Almen- } \\
\text { dro }\end{array}$ & $\begin{array}{l}\text { Oli- } \\
\text { var }\end{array}$ & $\begin{array}{l}\text { Otros } \\
\text { Frut. }\end{array}$ & $\begin{array}{l}\text { Total } \\
\text { Has. }\end{array}$ \\
\hline AGOST & 84 & 1349 & - & 4 & 30 & 100 & 8 & 400 & 20 & 6 & 2101 \\
\hline ASPE & 86 & 2777 & - & 77 & 206 & 134 & 32 & 392 & 5 & 4 & 3713 \\
\hline ELDA & 294 & 3 & 65 & 15 & 5 & - & - & 111 & 232 & - & 735 \\
\hline HONDON NIEVES & - & 340 & 540 & 72 & 100 & 60 & 2 & 86 & - & - & 1200 \\
\hline HONDON FRAILES & 14 & 14 & 20 & 20 & 55 & - & - & 5 & - & - & 128 \\
\hline \multicolumn{12}{|l|}{ MONFORTE } \\
\hline DEL CID & 10 & 3714 & - & - & - & 18 & 9 & 560 & 4 & - & 4316 \\
\hline MONOVAR & 73 & 20 & 1735 & 40 & 20 & 25 & 10 & 145 & 25 & 10 & 2103 \\
\hline NOVELDA & 40 & 2889 & - & - & 8 & 2 & 1 & 245 & 5 & - & 3190 \\
\hline PETREL & 11 & 46 & - & 7 & 10 & 4 & 1 & 7 & 39 & - & 125 \\
\hline LA ROMANA & 14 & 477 & 448 & 2 & 3 & 2 & - & 254 & 19 & - & 1219 \\
\hline \multicolumn{12}{|l|}{ VINALOPO } \\
\hline MEDIO & 626 & 11630 & 2808 & 237 & 437 & 345 & 61 & 2205 & 349 & 20 & 18830 \\
\hline BAÑERES & 40 & - & 158 & 5 & 2 & - & - & 24 & 20 & 10 & 259 \\
\hline BENEJAMA & 45 & 1 & 30 & 247 & 84 & 6 & 39 & 90 & 36 & 20 & 598 \\
\hline BIAR & 84 & 1 & 42 & 217 & 27 & 52 & 18 & 10 & 84 & - & 535 \\
\hline CAMPO DE MIRRA & 39 & - & 28 & 43 & 23 & 4 & 18 & 21 & 9 & - & 185 \\
\hline CAÑADA & 28 & - & 26 & 61 & 15 & - & 10 & 51 & 10 & - & 201 \\
\hline SALINAS & 10 & - & 40 & 280 & 2 & - & - & - & - & 5 & 337 \\
\hline SAX & 126 & 6 & 253 & 250 & 15 & - & - & 32 & 9 & - & 619 \\
\hline VILLENA & 3187 & - & 300 & 1913 & 90 & 20 & 10 & - & - & 20 & 5540 \\
\hline \multicolumn{12}{|l|}{ VINALOPO } \\
\hline ALTO & 3559 & 8 & 987 & 2971 & 258 & 82 & 97 & 227 & 142 & 55 & 8274 \\
\hline $\begin{array}{l}\text { TOTAL } \\
\text { COMARCAL }\end{array}$ & 4185 & 11638 & 3795 & 3208 & 695 & 427 & 158 & 2432 & 491 & 75 & 27104 \\
\hline
\end{tabular}

En base a tales datos se ha determinado la demanda teórica de 1970 a 1981 en los diferentes términos municipales. El resultado obtenido arroja una demanda teórica de 16,94 $\mathrm{hm}^{3}$ año para la última fecha. Se constata que durante el período de once años la variación de la demanda ha ido incrementándose hasta conseguir, siempre teóricamente, $3,49 \mathrm{hm}^{3} /$ año, cantidad que era necesario atender.

Sin embargo, los consumos reales de 1981, según los datos facilitados por las fuentes consultadas, arrojan un valor de $15,39 \mathrm{hm}^{3} /$ año de agua consumida; es decir, que en esta fecha el volumen demandado es inferior en $1,54 \mathrm{hm}^{3} /$ año $(90,86 \%)$ de lo teóricamente determinado. En realidad, la diferencia es mínima y está plenamente justificada por la crisis económica y la consiguiente [182]

${ }^{10}$ PLAN NACIONAL DE ABASTECIMIENTO Y SANEAMIENTO: Municipios inferiores a 1.000 habitantes consumen 120 1/hab./día; entre 1.000 y 6.000 habitantes 175 ; entre 6.000 y 12.000 habitantes, 200; entre 12.000 y 50.000 habitantes, 250 y, entre 50.000 y 250.000 habitantes, 350 litros/hab./día.

Las dotaciones teóricas futuras, aplicadas a los núcleos para 1990 son las siguientes: municipios inferiores a 1.000 habitantes, 160 litros/habitante/día; entre 1.000 y 6.000 habitantes, 220; entre 6.000 y 12.000 habitantes, 250; entre 12.000 y $50.000,3001$ y de 50.000 a 250.000 habitantes, 350 litros/habitante/día. 
CUADRO NUMERO 4

ESTRUCTURA DEL COSTO DE PRODUCCION DE UVA DE MESA

ALEDO EN NOVELDA

\begin{tabular}{|c|c|c|c|c|c|c|}
\hline \multirow[t]{2}{*}{ CONCEPTO } & \multicolumn{2}{|c|}{ Explotación tipo 1} & \multicolumn{2}{|c|}{ Explotación tipo 2} & \multirow[b]{2}{*}{$\%$} & \multirow[b]{2}{*}{$\%$} \\
\hline & Pesetas & $\%$ & $\%$ & Pesetas & & \\
\hline Tracción & 29.750 & 8.52 & 5,06 & 23.106 & 6,68 & 3,16 \\
\hline Mano de obra & 123.060 & 35.24 & 20,91 & 123.840 & 35,81 & 16,96 \\
\hline Materias primas & 196.441 & 56.25 & 33,38 & 199.020 & 57,51 & 27.22 \\
\hline Abonado & 33.543 & 9.60 & 5,70 & 16.384 & 4,73 & 2.24 \\
\hline Productos fitosanitarios & 42.598 & 12.20 & 7.24 & 47.198 & 13.64 & 6,46 \\
\hline Agua & 58.800 & 16.84 & 9,89 & 36.438 & 10.53 & 4,98 \\
\hline Embolsado & 24.000 & 6.87 & 4,08 & 24.000 & 6.94 & 3.28 \\
\hline Otros (estercolado, etc.) & 37.500 & 10.73 & 6.37 & 75.000 & 21,67 & 10,26 \\
\hline Gastos directos (1) & 349.251 & 100 & 59,35 & 346.066 & 100 & 47,34 \\
\hline Gastos generales & 7.236 & 3.41 & 1.23 & 95.955 & 26.79 & 13,13 \\
\hline Contribución e impuestos & 2.167 & 1.02 & 0,37 & 2.167 & 0.60 & 0,30 \\
\hline Segur. Social y Cuota Empres. & 11.037 & 5.20 & 1.88 & 11.037 & 3,09 & 1.51 \\
\hline Intereses (11\% s/cap. circul.) & 20.333 & 9.57 & 3.45 & 25.037 & 6,99 & 3,42 \\
\hline $\begin{array}{l}\text { Amortizac. Periodo } \\
\text { improductivo }\end{array}$ & 171.648 & 80.81 & 29.17 & 223.992 & 62.53 & 30.64 \\
\hline Gastos indirectos (2) & 212.421 & 100 & 36,10 & 358.188 & 100 & 49.00 \\
\hline Renta tierra (3) & 26.796 & - & 4,55 & 26.796 & - & 3,66 \\
\hline Gastos totales $(1)+(2)+(3)$ & 588.468 & - & 100 & 731.050 & - & 100 \\
\hline \multicolumn{7}{|l|}{ Producción (Kgs./Ha.) } \\
\hline Año medio & 13.500 & - & - & 17.550 & - & - \\
\hline Año 1982* & 15.400 & - & - & 20.020 & - & - \\
\hline \multicolumn{7}{|c|}{ COSTO DE PRODUCCION (Ptas./Kg.) } \\
\hline Año medio & 43,59 & - & - & 38.21 & - & - \\
\hline Año 1982 & 41,25 & - & - & 36.52 & - & - \\
\hline
\end{tabular}

-La explotación tipo 1 es la que se riega por inundación y la de tipo 2 es la que tiene sistema de riego por goteo.

-Se han considerado 4 años como período improductivo y 25 años de vida productiva.

-Los gastos generales incluyen la anualidad de amortización del capital fijo y sus gastos de conservación.

-El interés considerado tanto para el cálculo de las amortizaciones como intereses del capital circulante, es del $11 \%$.

-La encuesta se realizó el 15 de octubre de 1982, y por consiguiente los precios considerados son los corrientes de esa fecha.

-La producción del año 1982 se calculó por alfarrasado, cuyo error es mínimo, ya que los racimos se embolsan y su número es proporcional a la producción.

-Los cálculos de los costes de producción siempre se refieren a una ha. [183]

menor llegada de inmigrantes, unido a la política de restricción voluntaria de los últimos años. Es así como se puede entender que la capital provincial sólo consuma 272 1/h/d en 1981, Elche 190, Elda 260 y Villena 231 1/h/d, frente a los valores teóricos asignados.

Atendiendo a los consumos reales de 1981, en contraposición a los cálculos teóricos realizados, los municipios se fraccionan en dos conjuntos espaciales bien diferenciados. E1 primero lo integran los que en dicha fecha han superado las previsiones: Bañeres, Campo de Mirra, Cañada, Monforte del Cid, Petrel, Pinoso y Salinas. Éstos representan el 35\% del número de municipios, han consumido el $23,37 \%$ del agua y sólo acaparan el 20,87\% de la población de hecho. Su repercusión en la demanda futura es pequeña y fácil de atender.

El segundo lo componen el resto de municipios que no llegaron a utilizar los volúmenes asignados. Pero, en este segundo grupo conviene distinguir dos nuevos apartados. En primer lugar, aquéllos que consumen entre el valor medio de todo el conjunto, 90,86\%, y el valor 
teórico: La Algueña, Hondón de las Nieves, Monóvar, Novelda y Villena. Son los que representan al $25 \%$ de los municipios, han consumido el $34,25 \%$ del agua, bastante significativo, y, acaparan el 33,6\% de la población. Es, por tanto, un colectivo al que se le necesita ajustar la demanda hacia el futuro aunque el peso del mismo sea producto de la importancia de los tres últimos centros urbanos. El resto obtienen porcentajes bastante inferiores a los presupuestos teóricos. De ellos, es necesario destacar a Elda y Sax por el nivel de consumo por habitantes, por el volumen anual demandado y, porque si la crisis se supera, serán los municipios que más fácilmente pueden atraer a la población emigrante.

El balance total de la cuenca pone de manifiesto que el volumen de agua utilizada se eleva a $86,09 \mathrm{hm}^{3} /$ año y que su contribución porcentual es muy desigual entre los diferentes sectores productivos. Su reparto es del modo siguiente: $67,70 \mathrm{hm}^{3}$ para dotación de la superficie transformada y $18,39 \mathrm{hm}^{3}$ para abastecimiento industrial y urbano de los que tres $\mathrm{hm}^{3}$ no están conectados a la red de abastecimiento urbano.

Como resultado de todo el proceso se constata que frente a $\operatorname{los} 68,08 \mathrm{hm}^{3} /$ año renovables por término medio y únicos posibles de poder ser consumidos, la demanda real es de 86,09 $\mathrm{hm}^{3} /$ año, lo que arroja un déficit anual de $18,03 \mathrm{hm}^{3} /$ año. Hay una extracción superior a los recursos y ello implica una sobreexplotación permanente de las reservas.

Tal explotación se puede considerar bajo dos posibilidades: involuntaria, lo cual conduce al concepto de sobreexplotación o, voluntaria, lo que se traduce en una explotación minera del agua. Aquélla tiene el inconveniente de que el usuario no es consciente de que su explotación continuada puede conducirle al agotamiento con las repercusiones que le pueden sobrevenir. Sería obligado enseñar al agricultor o industrial a que planifique su explotación o industria con el objetivo de obtener el máximo beneficio económico con el mínimo de agua o, que se convierta en una explotación minera. Esta nueva modalidad de [184] explotación es una opción atrayente cuando la rentabilidad económica y social está garantizada.

Así pues, el uso actual del agua, según datos de 1981, se caracteriza de la forma siguiente: 1) la casi totalidad de sus aprovechamientos actuales se sacian mediante aguas subterráneas. 2) El uso agrícola es el que consume mayor cantidad, $67,70 \mathrm{hm} / \mathrm{año}$, el 78,63\% del total. 3) La calidad de las aguas hipogeas es generalmente buena, aunque algunas de las perforaciones realizadas a cotas por debajo del nivel del mar presentan progresiva salinización que provocan su inutilización.

\section{LA DEMANDA FUTURA DE AGUA}

\section{Necesidades para el sector agrícola}

La estimación de la demanda futura de agua presenta grandes dificultades puesto que está determinada por una serie de parámetros difíciles de precisar. Sin embargo, y, a pesar de los errores que se pueden cometer, es necesario la formulación de un nuevo modelo con dos objetivos: 1) conocer los valores máximos que se pueden necesitar y 2) saber cuáles son los sectores a los que más atención se debe prestar en la planificación hídrica futura. En principio, puede afirmarse que la demanda futura de agua en la agricultura depende de la superficie de posible transformación, del tipo de cultivo más rentable en cada momento, de las técnicas de riego, del precio del agua, de la comercialización de los productos agrarios, de los planes de desarrollo programados por el Gobierno y del mayor o menor impacto de la crisis económica sobre las industrias básicas de la zona y sus repercusiones en el empleo, dinámica poblacional, recursos financieros disponibles, etc.

En cuanto a la superficie posible de transformación se constata que existe espacio 
disponible tanto en calidad como en cantidad para que esta variable no resulte limitativa de la expansión. Por esto, el ritmo medio de transformación de secano a regadío en los últimos años ha sido de unas 1.000 ha/año de las que el 90\% corresponden al Medio Vinalopó, aunque en la actualidad hay tendencia a la desaceleración.

Referente a la variable rentabilidad de los distintos cultivos, desglosando su análisis por zonas, se observa que en el Medio Vinalopó la uva de mesa es rentable pero no el almendro y el olivo. Esto es debido a que los precios medios de cotización percibidos por el agricultor de los dos últimos productos han sufrido una regresión, dejando de ser viables. En consecuencia, la tendencia dominante es incrementar las plantaciones de uva de mesa. En los últimos años han sido unas 300 ha anuales, que proceden de nuevos regadíos y de la reconversión de superficies ocupadas de almendros y olivos en regadío. En el Alto Vinalopó los cultivos poco rentables, manzano y almendro, tenderán a disminuir su superficie ocupada. Además, existen limitaciones de tipo climático, por lo que se observan disminuciones de la superficie de almendro y [185] manzano y un ligero incremento de la viña de vinificación, herbáceos (cereales de invierno y primavera) y hortalizas de verano.

Las técnicas de riego y el precio del agua, por ser variables muy interrelacionadas, deben analizarse en común. El precio del agua está en función de la profundidad de captación, precio de la energía, evolución de los costes de mano de obra, etc. Es obvio decir que el costo del agua es lo bastante creciente para hacer limitativo su empleo en muchos cultivos, sobre todo en aquellos que tienen mayores necesidades de ella (manzano, hortalizas, etc.). Por tanto, objetivo primordial de cualquier agricultor será economizar su consumo mediante labores culturales o introduciendo nuevas técnicas de riego, por ejemplo el localizado (goteo, microaspersión, etc.), que ahorren importantes cantidades y la hagan rentable. El cultivo en donde se está observando una introducción progresiva del riego por goteo es la uva de mesa. Según el estudio efectuado sobre explotaciones tipo de este cultivo en el Medio Vinalopó, se comprueba que el ahorro en el consumo de agua es del orden de un 30\% (cuadro 4), puesto que la necesidad media (dos o tres riegos, según zonas) en su modalidad superficial es de $3.200 \mathrm{~m}^{3} / \mathrm{ha} / \mathrm{año}$, cantidad que se reduce a $2.300 \mathrm{~m}^{3} / \mathrm{ha} /$ año mediante goteo, según pone de manifiesto un calendario de riegos en zona de Novelda, elaborado para los casos más desfavorables climáticamente. Además, resulta que hay un considerable ahorro de fertilizantes, como se deduce del desplazamiento de los gastos directos del cultivo según tipo de explotación, en donde el tanto por ciento de gasto de agua del total de gastos directos baja del 16,84\% al 10,53\%, y el de fertilizantes del 9,60\% al 4,73\%. Si a estos ahorros de inputs, consecuencia de una óptima distribución y racionalización en el uso del agua y abonado, unimos un mayor rendimiento por unidad de superficie (Kgs/ha), encontramos la justificación de las inversiones realizadas en aras de una menor demanda futura de agua en el sector agrario.

En cuanto a la comercialización de los productos agrarios puede decirse que falta mucho camino por recorrer. No obstante, una de las soluciones necesarias para conseguir buenos precios, de interés especial para la gran mayoría de las numerosas explotaciones familiares de la comarca, es generalizar las Sociedades Cooperativas. En general, las Cooperativas tienen que seguir progresando si los propios agricultores desean elevar sus rentas, rebajando costos productivos (Cooperativas de riego, de suministros, etc.), mejorando los precios percibidos, a través de una adecuada comercialización, y estructurando e integrando las Cooperativas locales en una escala superior, de orden comarcal, cuyo tamaño y volumen de negocio posibiliten la tenencia de una adecuada red de información de mercados, gerencia profesional, etc.

Por último, referente a las repercusiones que sobre el desarrollo de la zona pueden tener los distintos planes elaborados por el Gobierno, verdaderos instrumentos de la política agraria, está claro que los Reales Decretos 1200/81 prolongación del promulgado en 1978 y el 200/82, además de la consideración de Comarca de Ordenación preferente en cuanto a prioridad en las 
inversiones del IRYDA, han supuesto incentivos valiosos para la modernización de [186] las explotaciones agrarias (instalaciones en riego por goteo, embalses reguladores, transformaciones de tierras de secano a regadío, etc.), al haber contado los agricultores con financiación a costes y plazos apropiados al período de maduración de las inversiones. A tales instrumentos hay que añadir las actuaciones comarcales del IRYDA con su política de mejoramiento de la infraestructura (nuevos sondeos, etc.), que unido al fomento del cooperativismo, han supuesto un espaldarazo al desarrollo agrario de la comarca.

Expuesta la tendencia de las diferentes variables se formulan dos hipótesis, mínima y máxima, sobre las necesidades hídricas futuras para atender a la agricultura.

La primera presupone que no se incremente la superficie regada de 1981 pero se admite la reconversión de unas 250 ha/año a uva de mesa en el Medio Vinalopó procedente del almendro y olivar. Igualmente se acepta que en Alto Vinalopó existirá una reconversión de 100 ha anuales hacia herbáceos que provendrán del manzano. Además, aproximadamente, unas 1.000 ha anuales de uva de mesa instalarán riego localizado. Bajo esta hipótesis la demanda teórica futura de agua en la comarca agraria del Vinalopó se situaría en $90,729 \mathrm{hm}^{3}$ en 1985 y 83,084 $\mathrm{hm}^{3}$ en 1990.

La hipótesis máxima considera el supuesto de que no existiera limitación de agua y que la evolución futura de la superficie a regar fuera semejante a la experimentada en los últimos años. En este caso, la demanda teórica futura se elevaría a $97,062 \mathrm{hm}^{3}$ en 1985 y a $105,4 \mathrm{hm}^{3}$ en 1990.

\section{Requerimientos para abastecimiento urbano e industrial}

El desarrollo agrícola, industrial y urbano experimentado en las dos comarcas se refleja a través del crecimiento de la población en el intercensal 1970-81. Ya se puso de manifiesto que el aumento sufrido presentaba dos momentos muy desiguales, siendo realmente expresivo el del último quinquenio. Como esta variable y su tendencia es la más importante para poder estimar la población futura, es necesario conocer su evolución entre 1975 y 1981. La tipología municipal es el resultado del crecimiento natural y el movimiento migratorio (Cuadro 5). Del análisis global se deduce que tres núcleos tuvieron un crecimiento negativo: Benejama, Campo de Mirra y Hondón de las Nieves. A ello se une que 12 de los municipios, el 60\%, arrojen un saldo migratorio negativo. La combinación de las dos variables demuestra que seis municipios tienen un crecimiento demográfico negativo. Como consecuencia, la población sólo aumentó en 11.234 habitantes de los que 2.789 son inmigrantes, mientras su pérdida se elevó a 1.721 personas.

Además, la inmigración, a pesar del aumento en el bienio 77-78, ha descendido en un $70 \%$ con respecto a la década anterior, que unido al pequeño crecimiento natural, $7,7 \%$, indica una tendencia futura que no rebasará el $0,5 \%$ acumulativo anualmente. Por esto se estima que en 1990 la población de las dos comarcas será de 210.597 habitantes. 
CUADRO NUMERO 5

TIPOLOGIA MUNICIPAL DEL CRECIMIENTO DE LA POBLACION

\begin{tabular}{|c|c|c|c|c|c|c|}
\hline \multirow{2}{*}{ Municipios } & \multicolumn{2}{|c|}{ Poblac. de hecho } & \multicolumn{3}{|c|}{ Crecimiento de la población } & \multirow{2}{*}{$\begin{array}{c}\text { Tipo } \\
\text { municipio }\end{array}$} \\
\hline & 1975 & 1981 & Vegetat. & Migrat. & Total & \\
\hline AGOST & 3.715 & 3.772 & 160 & $-27,73$ & 57 & $\mathrm{AD}$ \\
\hline ALGUEÑA, LA & 1.637 & 1.609 & 15 & $-26,27$ & -28 & $\mathrm{AD}$ \\
\hline ASPE & 14.385 & 15.291 & 885 & 1,46 & 906 & $\mathrm{AE}$ \\
\hline BAÑERES & 6.233 & 6.704 & 326 & 23,27 & 471 & AA \\
\hline BENEJAMA & 2.054 & 1.944 & -11 & $-48,20$ & -110 & DD \\
\hline BIAR & 3.041 & 3.203 & 133 & 9,54 & 162 & $\mathrm{AA}$ \\
\hline CAMPO DE MIRRA & 507 & 413 & -14 & $-157,80$ & -94 & DD \\
\hline CAÑADA & 1.096 & 1.099 & 5 &,- 83 & 3 & $\mathrm{AE}$ \\
\hline ELDA & 48.708 & 53.128 & 3.315 & 22,69 & 4.420 & $\mathrm{AA}$ \\
\hline HONDON NIEVES & 1.593 & 1.562 & -14 & $-10,68$ & -31 & DD \\
\hline HONDON FRAILES & 581 & 528 & 14 & $-116,32$ & -53 & $\mathrm{AD}$ \\
\hline MONFORTE DEL CID & 4.201 & 4.656 & 267 & 44,76 & 455 & $\mathrm{AA}$ \\
\hline MONOVAR & 10.857 & 11.140 & 314 & $-2,86$ & 283 & $\mathrm{AE}$ \\
\hline NOVELDA & 18.885 & 20.950 & 1.204 & 45,60 & 2.065 & $\mathrm{AA}$ \\
\hline PETREL & 20.424 & 20.612 & 1.234 & $-51,22$ & 188 & $\mathrm{AD}$ \\
\hline PINOSO & 5.178 & 5.218 & 171 & $-25,30$ & 40 & $\mathrm{AD}$ \\
\hline ROMANA, LA & 2.014 & 2.010 & 9 & $-6,46$ & -4 & $\mathrm{AE}$ \\
\hline SALINAS & 935 & 1.007 & 4 & 72,73 & 72 & $A A$ \\
\hline SAX & 6.520 & 7.336 & 444 & 103.07 & 816 & $\mathrm{AA}$ \\
\hline VILLENA & 27.493 & 28.735 & 1.386 & -3.29 & 1.296 & $\mathrm{AE}$ \\
\hline
\end{tabular}

Fuente: ALICANTE 1981. Datos y Series Estadisticas. INE.

(1) Censo de población 1 de marzo de 1981.

Las dotaciones teóricas futuras aplicadas a los núcleos urbanos son las especificadas en la nota $n .^{\circ} 10$. En base a dichos valores la necesidad de agua para usos industriales y servicios se elevará a $22,48 \mathrm{hm}^{3} /$ año.

Un análisis detallado de los municipios que más constribuyen a la demanda pone de manifiesto que sólo Elda acapara el 34,39\% del total. Pero si el territorio se parcela en base a la nueva ley de bases del Régimen Local, la Mancomunidad Intermunicipal del Vinalopó, en la que se agrupan Elda, Petrel, Monóvar y Sax, consumirá el 52,78\%, más de la mitad del caudal teórico. Se acentúa, por tanto, el desequilibrio en cuanto a número de municipios, población total y demanda, puesto que la Mancomunidad representa el 20\%, la población acaparada el 48,35\% y la necesidad de agua alcanza el 52,78\%.

\section{LA CONFORMACIÓN DE UNA POLÍTICA SOBRE AGUAS}

De la comparación entre los recursos hídricos y la demanda de agua surge el [188] balance hídrico que refleja la situación para la zona en un momento determinado.

La lluvia útil de todo el conjunto es de $68,06 \mathrm{hm}^{3} /$ año, pero este valor es engañoso. Así, dado que el Medio Vinalopó carece prácticamente de recursos y que sus reservas están siendo sobreexplotadas, dicha zona ha de quedar hidráulicamente ligada al Alto Vinalopó, debido a la dificultad en la llegada de caudales procedentes de otras cuencas hidrográficas.

El balance hídrico global (demanda menos recursos) en 1990 arrojará un déficit de $32,196 \mathrm{hm}^{3} /$ año dado que la demanda teórica, se estima siguiendo la hipótesis mínima, en 100,25 $\mathrm{hm}^{3} /$ año. Pero el balance se agudiza si contabilizamos los caudales que se extraen y se consumen fuera de la comarca. Y esta situación se agrava más si consideramos la segunda hipótesis cuyo balance arrojaría un déficit anual de $52,32 \mathrm{hm}^{3} /$ año, sin tener en cuenta los caudales exportados a otras áreas de la provincia (Riegos La Salud, S.A., etc.). La necesidad aumenta de 1981 a 1990 
en $14,16 \mathrm{hm}^{3}$. Como los recursos hidráulicos son limitados y están sometidos a la variabilidad de las precipitaciones y posibles contaminaciones, es urgente aprovecharlos de la manera más racional, técnica y económicamente. Se exige, por tanto, una planificación integral de los recursos superficiales y subterráneos, siendo imprescindible su evaluación para formular una política de agua que resuelva el problema de su escasez, sea rentable socialmente y no altere el medio ambiente.

El método más eficaz para aumentar las reservas es la construcción de embalses que retengan la aportación de las corrientes fluviales ${ }^{11}$. Tales presas tienen la ventaja de controlar las riadas, retener las lluvias torrenciales ${ }^{12}$ y escalonar su uso. También, el desarrollo de las técnicas de aprovechamiento permite explotar los almacenes interiores y realizar trasvases. Más recientemente «se reconoce la importancia de restringir la demanda y aumentar el rendimiento desde la extracción hasta su distribución final y uso último» ${ }^{13}$. Se trata, en consecuencia, de conseguir una óptima utilización de los recursos hídricos mediante una gestión plural, realizando las necesarias inversiones de capital para satisfacer sus deficiencias. [189]

En base a todo lo expuesto estimamos que los principios directos de la política de agua en la comarca agrícola e hidráulica del Vinalopó deben apoyarse en las siguientes acciones: 1) evitar que aumenten las extracciones; 2) impedir, en lo posible, la salida de agua de cualquiera de los acuíferos a otra zona; 3 ) procurar la construcción de depuradoras; 4) incorporación de la tecnología más avanzada con especial incidencia en los cultivos consumidores de poca agua, riegos localizados y aprovechamiento de caudales residuales; 5) utilizar los medios de comunicación social para explicar la situación a la que puede conducir el ritmo de consumo; y 6) si con todo no se soluciona, pensar en la necesidad de realizar un trasvase.

Respecto al primero de los principios, la acción más inmediata a tomar está encaminada a evitar que aumenten las extracciones. Es necesario mantener, como máximo, el actual volumen de extracción con el fin de recuperar parte de los caudales consumidos.

La solución pasa por una nueva Ley de Aguas que fije el concepto de agua como bien público y de toda la comunidad nacional, lo que equivale a decir que las Comunidades Autónomas no podrán actuar sobre la cuenca de sus ríos, sino la Administración Central. Además, al contemplar la unificación de la política de aguas en un único departamento ministerial se podrá realizar una planificación hidrológica que contenga, a través del Plan Nacional de Obras Hidráulicas, la coordinación de los diferentes planes de Cuenca y posibilite las transferencias de caudales. Es así como se podrá conseguir el aprovechamiento racional y equitativo de la cuenca al tiempo que se protege la calidad de vida y defiende el medio natural.

En segundo lugar se debe impedir la tradicional exportación de agua a otros municipios localizados fuera de la cuenca. En 1974 se enviaban 36,6 hm³/año desde el Alto al Medio y Bajo

${ }^{11}$ El pleno del Ayuntamiento de Agost aprobó en septiembre de 1983 la construcción de tres presas que podrán embalsar 2,5 $\mathrm{hm}^{3}$. La zona donde se proyectan las presas al estar rodeadas de montes desprovistos de vegetación corren peligro de que se depositen arenas y sólidos arrastrados por las lluvias de fuerte intensidad horaria, por lo que en pocos años se inutilizarían. Por esto, se debe planificar una ordenación del territorio implantando vegetación, preferentemente arbustiva (arbustos), que se acomoden a las curvas de nivel con el objeto de aguantar la tierra. Se puede realizar, en base a una utilización clara del desempleo, mediante su aportación de trabajo a obras de interés comunitario financiadas por el Estado.

12 JUÁREZ SÁNCHEZ-RUBIO, C. y VALDÉS PASTOR, M.: «Repercusión agraria de las inundaciones de 1982» en Lluvias torrenciales e inundaciones en Alicante. Instituto Universitario de Geografía. Universidad de Alicante. Instituto Universitario de Geografía. Universidad de Alicante. Alicante 1983 págs. 121-128.

${ }^{13}$ AMBROGGI, R. P.: «Agua». Investigación y Ciencia, 1980 número 50, pág. 65. 
Vinalopó y a la zona de Alicante ${ }^{14}$. Concluida la primera fase del trasvase Tajo-Segura, cuyo objetivo velado era dotar de agua a los centros turísticos e industriales del Sureste, la comarca del Vinalopó se podía ver beneficiada al poder liberar parte de los caudales que Aguas Municipalizadas venía utilizando para abastecer la ciudad de Alicante y su contorno, así como los aprovechados por el Canal de la Huerta de Alicante y zona dominada por el trasvase.

Esto es un hecho porque toda el agua que consume la capital de la provincia, $25 \mathrm{hm}^{3} / \mathrm{año}$, proviene del Tajo a través de la Mancomunidad de Canales del Taibilla. Sin embargo, lo realizado difiere de lo proyectado, ya que la prolongada sequía de la cuenca del Tajo ha obligado a seguir explotando los sistemas acuíferos del Vinalopó. Por tanto, no se liberan caudales sino que al [190] disminuir la reserva su coste de extracción es mayor, la calidad es inferior (necesidad de mezclar) y, en consecuencia, el volumen importado es menor, obligado y coyuntural.

No sucede lo mismo con Elche, ya que Riegos de La Salud, S.A., extrae siete tallas (módulos de 50 1/sg), 350 1/sg, de los que 100 1/sg se destinan al consumo urbano y agrícola de Hondón de los Frailes y los restantes 250 1/sg son para el consumo urbano y agrícola de Orihuela, Albatera, Crevillente y Elche. El volumen consumido fuera del Vinalopó asciende por este motivo a 7,88 hmªño. También la S.A.T. San Enrique extrae del término de Aspe un $\mathrm{hm}^{3} /$ año para consumo agrícola de Elche. Además, con destino al uso urbano e industrial de Elche se importa del área de Villena $2,55 \mathrm{hm}^{3} /$ año. En resumen, la exportación asciende a 11,43 $\mathrm{hm}^{3} /$ año que, unidos al déficit ya señalado de $32,196 \mathrm{hm}^{3}$, arroja un valor de $43,626 \mathrm{hm}^{3} /$ año para 1990.

En tercer lugar, procurar la construcción de depuradoras con el objeto de conseguir la utilización total de las aguas residuales urbanas. En este sentido, la iniciativa de la capital de provincia se ha hecho realidad en el Medio Vinalopó, donde la depuradora de Elda-Petrel regenera cada día un volumen medio de $10.500 \mathrm{~m}^{3}$. En época normal la cantidad reciclada oscila entre 11.000 y $11.500 \mathrm{~m}^{3} /$ día y durante las vacaciones de la industria se reduce a 6.500 ó 7.000 $\mathrm{m}^{3} /$ día.

Este caudal aumentará considerablemente cuando se conecten a la misma las aguas de Monóvar y Sax, cuyos municipios se han mancomunado con los anteriores. Tal recurso no tiene, actualmente, aprovechamiento alguno, ya que se vierte totalmente al cauce del Vinalopó. No obstante, pronto será utilizado por una Sociedad de regantes de Monforte del Cid para uva de mesa. La aplicación práctica de esta reutilización es totalmente aconsejable porque son caudales que cumplen una triple función: utilizados por la industria y uso urbano, aprovechados por la agricultura y consumidos en la comarca.

La mejor utilización del agua se concreta en tres aspectos. En principio se debe tender al aprovechamiento agrícola de cultivos que requieran pocos caudales para asegurar la producción. En este sentido se han puesto de manifiesto los cambios originados con el deseo de buscar una mayor utilidad y menor consumo. Por ello, el mejor uso del suelo en el Alto Vinalopó se cifra en los cereales de invierno y primavera y las hortalizas de verano. En el Medio Vinalopó la uva de mesa ocupa cada vez mayor superficie a costa de olivos y almendros. En segundo lugar se debe procurar aumentar el espacio dominado por el riego localizado, ya que es el procedimiento más idóneo para ahorrar agua puesto que los sistemas de riego tradicionales ofrecen muy poco rendimiento. Tal práctica se está extendiendo en la uva de mesa dada la escasez de agua y su precio creciente (vid, cuadro 4). Esta modalidad aprovecha la casi totalidad

\footnotetext{
${ }^{14}$ INSTITUTO GEOLÓGICO Y MINERO DE ESPAÑA: Investigación Hidrogeológica de la Cuenca Baja del Segura, Madrid 1979. Pág. 36. Del Alto Vinalopó se envía actualmente al exterior un volumen de $36,6 \mathrm{hm}^{3} / \mathrm{año}(\mathrm{de}$ los que 17,2 $\mathrm{hm}^{3}$ /año van al Medio y Bajo Vinalopó y 19,4 a la zona de Alicante, para abastecimiento público 10,6 $\mathrm{hm}^{3 / a n ̃ o ~ y ~ r i e g o s ~} 26 \mathrm{hm}^{3} /$ año).
} 
del caudal, requiere poca mano de obra, ahorra abono y suprime, en muchos casos, la instalación de motobombas. Los resultados ya se han puesto de manifiesto: ahorro de un $30 \%$ de agua, disminuye el gasto de [191] fertilizantes en un 50\%, se obtiene mayor rendimiento por unidad de superficie y se eleva la productividad.

Por último, el agua regenerada, tanto la de la zona como la procedente de otras áreas geográficas, debe ser en su totalidad para uso agrícola. La cuenca media recibirá anualmente, en un primer momento, 1,5 hm 3 /año procedente de Alicante con destino a Agost y Monforte del Cid. Son caudales que se reutilizan (depuradora Elda-Petrel) o ingresan en la Comarca, contribuyendo a paliar la situación adversa por la que pasa.

Se deben utilizar todos los medios de información pública para llevar a la conciencia de los entes locales que es imprescindible ahorrar agua. También, que es necesario incorporar los avances técnicos para reducir la demanda, pero sobre todo, que es de vital importancia la solidaridad en el consumo. Es obligado adecuarse a la propuesta formulada por la Organización Mundial de la Salud, que establece como nivel el consumo diario de 200 litros por habitante.

En sexto lugar es necesario realizar un balance definitivo de la comarca para ver los valores de la demanda y la oferta con el deseo de equilibrar la ecuación.

Hemos dicho que la lluvia útil es de $68,06 \mathrm{hm}^{3} / a$ ano. También se recuerda que este volumen se consigue porque la efectividad de la precipitación es mayor en el Alto que en el Medio Vinalopó. Pero, todos los años no puede asegurarse dicha cantidad, ya que la variabilidad interanual de las precipitaciones es muy grande (Villena 5,37; Sax 4,01 y Novelda 4,6).

Para 1990 la comarca tendrá unas disponibilidades adicionales de unos $15 \mathrm{hm}^{3} /$ año procedente de la reutilización de las aguas de la Mancomunidad del Vinalopó (Elda, Petrel, Sax y Monóvar), Villena y Agost (se incluyen los $2,5 \mathrm{hm}^{3}$ que se pretenden embalsar en Agost). A este volumen hay que añadir el envío procedente de Alicante al aprovechar la infraestructura que se está montando actualmente, y que pretende elevar hasta la cota de 505 m.s.n.m. en Agost y $425 \mathrm{~m}$. en Monforte del Cid, lo que viene a significar que el Medio Vinalopó estará completamente dominado. Además, la cantidad se puede incrementar muy considerablemente cuando entre en funcionamiento la depuradora de la Orgegia, con la que se completará la total reutilización de las aguas fecales que evacuan la ciudad de Alicante, Albufereta, Campello, Playa de San Juan, Villafranqueza, etc. Ante esta perspectiva estimanos que la comarca podrá recibir anualmente un caudal de $15 \mathrm{hm}^{3} /$ año, quedando asegurado el suministro de agua a los regadíos del Campo de Alicante como a sus futuras transformaciones.

Comprobado que el balance hídrico global de la comarca (consumo más exportaciones menos disponibilidades) arroja un déficit anual de 13,62 hm³/año, según la hipótesis mínima de no incremento de la superficie regable, consideramos que no es aconsejable la ampliación de regadíos en base a su alto grado de incertidumbre (sobreexplotación y descenso de niveles con peligro de salinización). [192]

La situación de la zona (altitud media de 350 m.s.n.m.), alejada del trasvase Tajo-Segura, determina que cualquier incremento de los volúmenes utilizados deba ser, exclusivamente, para atender los aumentos en la demanda de uso urbano e industrial. En tal sentido, y desde un punto de vista económico, la mejor estrategia será desplazar el uso del agua desde la agricultura, en la que se obtiene un valor añadido bajo por agua empleada, a la industria y servicios con un valor mucho más alto. Ante esta situación y, aun cuando fuera nula la tasa de crecimiento económico, la demanda continuaría aumentando. No obstante, al disponer de reservas podrían explotarse mientras se buscan nuevas alternativas tendentes a paliar el déficit hídrico comarcal.

La única solución para resolver el problema de la comarca pasa por la importación de recursos hídricos exteriores a la cuenca. Entre las alternativas que se pueden contemplar, dos reúnen las mejores posibilidades: el trasvase Tajo-Segura y el trasvase Júcar-Vinalopó, sin entrar en la valoración de su viabilidad técnica y económica. 
La primera de éstas, el denominado Aprovechamiento conjunto del trasvase Tajo-Segura, contemplaba en la Ley 21/1971 que en la segunda fase la provincia de Alicante se vería beneficiada con una dotación adicional de $70 \mathrm{hm}^{3} /$ año que podrían consumirse en cualquier comarca. Sin embargo, la promulgación de la Ley 52/1980 de 16 de octubre por la que se establece la «Regulación del Régimen Económico de la Explotación del Acueducto Tajo-Segura», especificaba la posibilidad de uso con fines urbano-industriales y ordenaba su funcionamiento. Igualmente plantea una política tarifaria autosuficiente e introduce la consideración de caudales excedentarios para las dotaciones a trasvasar.

Como la realidad dista mucho de los objetivos marcados por la Ley 21/1971, y los caudales asignados de la primera fase han sido muy inferiores a los promulgados, está claro que es inviable la realización de la segunda fase, que paliaría el déficit de esta Comarca. En caso de que llegara el agua, al ser necesario elevarla 300 metros más (ya ha sido elevada entre 400 y 500 metros hasta su consumo en la provincia de Alicante), su utilización sería para abastecimientos de población y usos industriales ${ }^{15}$. Como consecuencia, la viabilidad de esta alternativa es mínima o ninguna.

La segunda alternativa contempla la posibilidad de importar recursos hídricos del río Júcar. Según estudios efectuados el Júcar vierte al mar, aproximadamente, $250 \mathrm{hm}^{3} / \mathrm{año}$, de los cuales unos $100 \mathrm{hm}^{3}$ llegan al mar tras regar la zona arrocera de la Ribera del Júcar (Valencia) y otros $150 \mathrm{hm}^{3}$ se pierden sin aprovechamiento alguno. Parte de esta enorme riqueza potencial podría trasvasarse a la Cuenca del Vinalopó para ser aprovechada por los municipios que la integran y presentan déficit hídrico. En tal sentido, se ha pronunciado [193] el pleno del Ayuntamiento de Elche, señalando la posibilidad de construir un canal que salvase los $87 \mathrm{Km}$ que separan el río Júcar del Vinalopó en Villena. Sin embargo, sería aconsejable, según los ecologistas, que el enganche se hiciera antes de que el agua arribara a la central nuclear de Cofrentes, por considerar que en caso de contaminación de los caudales, podrían dañar irreparablemente a la zona de posterior uso.

Es así como se puede solucionar el déficit hídrico estructural que presenta la comarca y cuyas necesidades estimadas son las derivadas de la hipótesis máxima. Por tanto, consideramos que los recursos a trasvasar, a la comarca objeto de estudio, se elevan a $40 \mathrm{hm}^{3}$ por año. Esta alternativa es la más viable desde el punto de vista de una planificación de los recursos hídricos totales de la Comunidad Valenciana, ya que optimiza económica y socialmente su aprovechamiento. Además, se debe considerar que la Cuenca del Vinalopó, al estar integrada administrativamente en la del Júcar, la ejecución del plan propuesto es más factible al afectar solamente a esta Comunidad. Pero, tal vez, esta propuesta tan clara desde una óptica de rentabilidad socioeconómica, que además instaura una solidaridad intrarregional en una Comunidad en donde sus provincias han vivido de espaldas entre sí, no sea bien valorada y aceptada por las personas a las que compete su ejecución.

\footnotetext{
${ }^{15}$ MORALES, A. y JUÁREZ, C.: «Cambios en el uso del agua» op. cit. Pág. 389. En cuanto las primeras aguas han empezado a circular por el trasvase, su utilización ha sido, en principio, para abastecimiento de las poblaciones y en segundo lugar para usos industriales.
} 